ENTREVISTA

\title{
CULTURA, IDEOLOGIA, PODER E O FUTURO DA ANTROPOLOGIA
}

\author{
Eric R. Wolf
}

Eric Wolf está terminando seu livro provisoriamente intitulado Envisioning Power. Em uma tarde de inverno em N ova Iorque, Wolf conversou com Gustavo Lins Ribeiro sobre seu novo trabalho. A partir de uma análise do sacrifício humano entre os aztecas, do potlatch entre os kwakiutl e da mobilização para a guerra dos nazistas, propõe uma interpretação do poder das elites baseada em um diálogo entre as noções de ideologia e cultura. Aqui, Wolf mais uma vez demonstra sua grande erudição enquanto antropólogo heterodoxo e ávido leitor de muitas outras disciplinas. Enfrenta, igualmente, algumas das questões mais candentes para o futuro da antropologia: como relacionar o particular e o universal em uma era de globalização acentuada? Qual a importância da observação direta na prática da pesquisa de campo e para o perfil da antropologia enquanto disciplina com rosto próprio? Eric Wolf também tece comentários sobre o fim do socialismo real e aborda velhos e novos problemas do marxismo. Porém, o que esta entrevista traz claramente à tona são os esforços de um dos mais brilhantes antropólogos de sua geração para dar conta de algumas das questões clássicas da antropologia, como o poder da imaginação humana de estabelecer projetos que transcendem tempo e espaço.

\section{Lins Ribeiro}

Você pode nos falar sobre o livro que está terminando de escrever?

\section{Wolf}

Está sendo elaborado a partir dos cursos que dei no Graduate Center da City University of New York sobre ideologia e seus problemas. Há várias questões de pano de fundo. Uma delas é a de como se fazer uso de uma noção marxiana de ideologia. É uma idéia útil, de forma que a antropologia deve se interessar por ela. Sempre houve um vácuo entre a noção antropológica de cultura e uma abordagem político-econômica. As duas não se misturam. Eu pensei que explorando a noção de ideologia talvez pudéssemos buscar uma maneira de combinar um interesse em poder e idéias, encontrando quais são as relações entre ambos. Enfocando essa questão, talvez pudéssemos colocar juntas essas duas diferentes perspectivas.

\section{Lins Ribeiro}

Eu sei que você está trabalhando, nesse livro, com kwakiutls, aztecas e nazistas...

\section{Wolf}

Sim, tenho de voltar a um antigo artigo do Kroeber em que ele fala da possibilidade de se fazer uma investigação naturalista sobre a natureza humana mediante a percepção dos limites extremos de certos tipos de casos. Ele usou os sa- 
crifícios humanos dos aztecas como um tipo de situação-limite. Através dos casos extremos poderíamos notar características que em outras culturas e sociedades estariam escondidas, subterrâneas. É uma idéia interessante. Assim, esses três casos foram selecionados porque mostram formações ideológicas e fenômenos culturais em formas extremas. Não tento fazer uma comparação evolutiva, apesar de que se encaixam em uma tipologia do tipo "chiefdom", estado arcaico e moderno Estado-nação. Estou mais interessado na justaposição e não na comparação. Não sigo os mesmos elementos através dos casos. $\mathrm{Na}$ verdade, tento verificar o que em cada um deles tornou possível o crescimento dos traços diferenciados. Realmente comecei com os aztecas. J ulguei que seria interessante fazê-lo, em parte porque já havia trabalhado na M esoamérica antes. Assim, já conhecia, de alguma forma, esse material. A seguir, voltei-me para os nazistas, um assunto que também me era familiar, simplesmente porque tive de viver esse período. Os kwakiutl, por sua vez, surgiram de um curso, o último que dei no Graduate Center, "Etnografia e Teoria". Selecionei um certo número de casos e constatei como diferentes pessoas haviam interpretado distintamente os dados etnográficos. Os casos foram escol hidos de forma mais ou menos aleatória, mas existe uma certa semel hança entre eles.

\section{Lins Ribeiro}

E qual é essa semelhança?

\section{Wolf}

Ainda não tenho certeza. Estou fazendo o seguinte com o livro. Uma discussão teórica do problema de tentar integrar o marxismo, a economia política, com a cultura; o porquê de as duas coisas não se ajustarem e como se poderia então combiná-las. A seguir, vêm os três casos, já os reescrevi muitas vezes. Uma das coisas que acontecem é que quando trabalho em um caso, certas questões aparecem, e estas devem ser levantadas para os outros materiais. Eu sempre reviso meu trabalho vezes e vezes seguidas. Agora estou trabalhando em uma conclusão. O problema das conclusões é que, de uma certa forma, elas são muito banais. Isto é, em cada um desses três casos, o problema básico colocado é como você arranja as coisas, ou organiza as pessoas de maneira a maximizar as oportunidades de vida.

O potlatch resulta ser não apenas a oferenda de presentes - e isto não é uma descoberta minha, mas de pessoas que têm trabalhado na costa noroeste -, mas, também, a transmissão de substância das almas, poder espiritual de um grupo para o outro. Assim, todas aquelas peles de animais e cobertores são embrulhos de material invisível que estão sendo dados de um grupo para o outro. Poder-se-ia dizer que o problema é como fazer a vida a partir da morte, como vencer a morte. E o caso kwakiutl é muito interessante porque é, de fato, um fenômeno do século XIX - estavam sendo abalados por assentamentos e invasões coloniais. Os chefes estavam perdendo poder porque uma economia alternativa estava penetrando e os jovens se dirigiam para a pesca comercial ou para a cidade de Victoria, onde abriam bares ou se engajavam na prostituição. Os chefes estavam perdendo o controle. Então, o aumento do potlatch precisa ser visto como uma resposta a uma crise cultural real por intermédio da qual os chefes lutavam por seus poderes. Eles estão demonstrando que são realmente os organizadores do universo. Mas já estavam perdidos.

No que diz respeito ao caso azteca, temos de notar que o sacrifício humano 
é muito mais antigo do que os aztecas que são recém-chegados ao poder. Mas, para demonstrar que são os legítimos ocupantes do poder isto é o que fazem. E acaba se tornando a resposta geral para todos os problemas da vida: o calendário requer sacrifício humano, a guerra requer sacrifício humano. Existe, então, esse ciclo contínuo de violência que prossegue relacionado, em parte, à necessidade de fazer o tempo fluir em intervalos regulares. É preciso matar as pessoas para que os deuses venham e representem o próximo ciclo de tempo, e outro grupo vem... e assim por diante. O poder central do Estado se apossa dessa função de regular a seqüência do calendário. Quanto mais complicada a sociedade se torna e quanto mais expande seu poder sobre outras regiões, mais exacerbado se torna esse sistema. Tenochtitlán, a Cidade do M éxico, expande-se de um bando de cabanas de pau-a-pique no começo do século XIV para uma cidade de 150 mil, 200 mil habitantes. É preciso integrar todo esse povo e o calendário faz isso: organiza áreas da cidade, suas atividades, em linha com os sacrifícios humanos. Existe, então, uma expansão urbana e uma expansão política que alimentam esse tipo de violência.

Já sobre os nazistas, há muitas maneiras de se falar sobre eles, mas tratase aqui da organização da sociedade para a guerra. Não necessariamente para fazer a guerra contra outros povos, mas para organizar as pessoas de tal maneira que as atividades sejam realizadas ordenadamente, de uma forma quase militar. Os participantes treinam seus corpos e mentes para fazerem parte desse processo. À medida que isso se expande, cria-se esse corpo comunitário puro que deve continuamente extirpar os diferentes, pessoas que não se ajustam. Louis Dumont fez um comen- tário interessante. Ele apontou para o fato - provavelmente a primeira pessoa a fazê-lo - de que todo esse movimento não era apenas voltado contra os judeus, dirigia-se também contra os alemães, já que Hitler disse que os alemães agora são compostos de cinco ou seis raças, al gumas delas não valendo nada, outras sendo muito mais significantes. É um movimento de purificação do corpo social através da violência. Em última instância, as pessoas que avançam e transformam isso em um objetivo são aquelas capazes de implementar a violência e a guerra. E não existe uma luz no fim do túnel; não existe a promessa de um futuro melhor, para dizê-lo assim. Essa é a maneira como a vida é, a luta de todos contra todos, e os que obtêm sucesso só o fazem porque subjugam outras pessoas. $\mathrm{E}$ isto fica mais claro nas palavras de Hitler: "não estávamos à altura da tarefa que nos impusemos e, em um certo sentido, os soviéticos são superiores a nós porque são vencedores".

\section{Lins Ribeiro}

Você disse que o seu problema principal era capturar a relação entre ideologia e poder. Quando você se detém nos três casos, como vê essa relação operando?

\section{Wolf}

Em cada caso existe um objetivo imaginário. E este objetivo imaginário está sendo implementado via poder. A ideologia delineia a possibilidade imaginária. Em um determinado nível, imaginar não é loucura... Na verdade, eu venho tentando contornar esse problema. Essas são todas criações da imaginação humana. Alguém pensou e um número de pessoas cooperou na produção desses corpos de idéias. Mas elas são realmente o que Castoriadis chama l'ima- 
ginaire. Assim, a ideologia tem essa qualidade de l'imaginaire, relacionada com o poder. Porque os chefes, os dirigentes do Estado azteca, a elite nazista vêem a si mesmos como executores de projetos. E, em todos os casos, são projetos sem fim, não existe o dia em que se dirá: agora paramos com o sacrifício de pessoas. Já os chefes kwakiutl estão ansiosos por mostrar quem são. Em uma situação de perda de população há também recém-chegados que têm dinheiro da nova economia capitalista. Por exemplo, a existência de um homem que coletava de Boas taxas de informantes e mandava suas mulheres para trabalhar em prostituição em Victoria. Ele começa a ter um papel no sistema de potlatch e os antigos chefes o vêem como um arrivista. Fazem, então, um potlatch em que destroem grande quantidade de propriedades, de riquezas, e esse homem não consegue responder à altura. Assim, os antigos chefes fazem com que ele retorne a um status comum. Mas cada vez que isso ocorre, a quantidade de riquezas que tem de ser colocada em circulação também aumenta. Trata-se de um beco sem saída.

\section{Lins Ribeiro}

Eu estava pensando sobre o nexo entre ideologia, poder e cultura. Você faz uma clara relação entre ideologia e poder, mas onde colocaríamos a cultura?

\section{Wolf}

Em cada um dos três casos, as noções que legitimam as ideologias são retiradas daquilo que pensamos ser a cultura. No caso kwakiutl, a relação básica é a busca de poder espiritual, ganhar influência e poder indo à praia, encontrando o sobrenatural, lutando contra o sobrenatural, entrando em relação com o sobrenatural. Os chefes são as pessoas que recebem esse tipo de poder no princípio dos tempos. O animal ancestral tira sua pele e dá a pele, a máscara, os implementos para que eles sejam chefes. Estas são todas idéias que estão sob a rubrica do que chamamos de cultura. Entre os aztecas também. O calendário é extremamente antigo na M esoamérica e a noção de que o tempo não flui por si mesmo, que precisa ser levado, que tudo está organizado em termos de relações entre espaço e tempo, de maneira que você se ordena em relação a pontos no ambiente e em situações rituais com o Leste, Oeste, N orte e Sul. Onde as pessoas sentam em uma casa ou em uma reunião tem a ver com o posicionamento com o Leste e o Oeste. Quando funcionários do governo mexicano são convidados para sentar com os índios, eles são colocados no lado Oeste do recinto e, eles não sabem disso, estão sendo basicamente empurrados para uma posição inferior. Assim, o que costumávamos chamar de cultura é a matéria-prima a partir da qual essas ideologias são construídas e ganham influência, em parte, através disso.

\section{Lins Ribeiro}

N esse caso, o conceito de ideologia engloba o de cultura e, de certa forma, o dilui...

\section{Wolf}

A ideologia seleciona do plano mais geral da cultura aquilo que Ihe é mais adequado, o que pode atuar como marcas, símbolos ou emblemas de relações que se quer destacar.

\section{Lins Ribeiro}

O conceito ou noção de cultura nunca foi um ponto pacífico. Na verdade, é um campo de batalha. Talvez nos últimos dez ou vinte anos, o ponto mais quente desse campo de batalha nos EUA tenha sido a relação entre estudos culturais e 
antropologia que teve uma série de implicações para a antropologia, sobretudo para a antropologia norte-americana. Poderia explorar essa idéia de que o conceito de cultura é um locus de conflitos entre diversas disciplinas?

\section{Wolf}

Na história da noção de cultura, há que destacar uma pessoa, Herder, geralmente associado aos princípios dessa noção no final do século XVIII, começo do XIX. Herder era um alemão da área do Báltico, uma área de fronteira com poloneses, falantes do alemão, lituanos, estonianos, finlandeses. Assim, a noção de diferença revela-se importante na criação da noção de cultura. Herder interessou-se por aquilo que mais tarde foi chamado de folclore, de literatura folclórica. Ele tentou definir o que era o espírito interior que distinguia um grupo do outro. Os finlandeses tinham o seu espírito, os alemães o deles. 0 momento inicial dessa idéia se relaciona com a situação política de ausência de um Estado-nação alemão unificado. De modo que a concepção de uma forma de unidade espiritual entre os alemães precede a formação do Estado, ao contrário do que aconteceu na França, onde o Estado possui uma unidade e, em conseqüência, todos se tornam cidadãos daquele Estado. Assim, a noção de cultura sempre se encaixa em situações em que, por um lado, há diferenças entre a população, e por outro, apelos políticos à unidade, soberania, dominação etc. Existe sempre a idéia que sob os diversos elementos da cultura - comida, habitação, vestuário, sistemas de crenças - há alguma forma de espírito interior. E, claro, esse espírito interior necessita trabalhar através de uma elite que o expresse. Isso não seria para os camponeses... Então, existe uma agenda política embutida em tudo isso e que foi desconhecida nos primórdios da antropologia. Quando Boas toma essas idéias e as traz para os Estados Unidos e o Canadá, todo mundo passa a ter sua própria cultura. Mas a agenda política de alguns grupos tentando definir espaço e poder para eles mesmos não é considerada.

\section{Lins Ribeiro}

Em certo sentido, quando a noção de cultura é apropriada pela antropologia ela é despolitizada.

\section{Wolf}

Sim, ela é despolitizada. Já os estudos culturais fizeram duas coisas importantes. Uma é mostrar a cultura enquanto construção, não se trata mais de um espírito interior que movimenta a todos essa é uma tendência geral que, na verdade, não se restringe aos estudos culturais. A outra é que, rapidamente, se levantam questões sobre hegemonia: quem impõe essas idéias a quem, quem está inventando os cânones, as regras que definem os jogos, existem contrajogos? Feminismo, os afro-americanos, qualquer que seja o tipo de afirmação. Assim, os estudos culturais focalizaram nos pontos fracos do conceito antropológico de cultura. Mas eu acho que a fraqueza deles é o exagero no que diz respeito à construção, exagerando, em conseqüência, a concepção de uma elite que se estabelece e que constrói hegemonia mais ou menos como quiser. Mas há algo sobre o conceito de cultura que não explicamos bem para nós mesmos. E talvez eu esteja falando sobre isso porque ensinei "cultura e personalidade" por tantos anos. Psiquês e corpos tomam forma via socialização e cultura. Você aprende a andar, falar, comer e o que comer, o que é aceitável e o que não é, o que é prestígio e o que não é, o que é moral e o que não é. O conceito 
de cultura possui suas próprias camadas. Existem traços, como formas de enterrar as pessoas, de comer certos alimentos. Esse conceito também inclui múltiplas realidades imperativas que são sempre formadas e trabalhadas. A história alemã fornece um desses exemplos, de como camponeses eram levados às igrejas onde eram forçados a confessar, se não o fizessem se tornavam fora da lei. Isto é, existem maneiras através das quais forças externas nos constroem enquanto vivemos. $M$ as a natureza do que subjaz ao contato entre essas forças é algo que creio ser altamente real. Os que falam dos espíritos dos alemães, finlandeses e estonianos, colocam essas questões em uma linguagem literária extremamente sofisticada. M as existe algo na experiência de crescer em uma cultura que cria diferenças, cria hábitos que não são os mesmos do outro lado da fronteira. $\mathrm{E}$ esses pontos de ancoragem se tornam importantes. A idéia que os nazistas tinham de transformar alguém em um soldado permanente, só poderia vingar em um lugar onde ser um soldado significava prestígio e recompensas, onde as pessoas tinham essas experiências e os velhos conversavam sobre como era ser um soldado vitorioso contra os desajeitados franceses etc. Dessa forma, o conceito de cultura esconde uma quantidade tremenda de relações interessantes.

\section{Lins Ribeiro}

É como se às vezes fosse abstrato em excesso, às vezes ao contrário.

\section{Wolf}

Mas o que me chama a atenção nos estudos culturais é que tudo parece ser "manufaturado", uma espécie de fraude imposta a outros.

\section{Lins Ribeiro}

Também, marcados pela análise literária, não dão suficiente atenção àquilo que chamamos de realidade etnográfica.

\section{Wolf}

E claro que essa realidade etnográfica opera com oportunidades e constrangimentos que são aprendidos. É como um rato correndo em um labirinto que aprende como sair dele e chegar ao queijo.

\section{Lins Ribeiro}

Falemos da consciência de coisas maiores do que aquelas que o observador constata. A cho, por exemplo, que noções como níveis de integração sociocultural, de J ulian Steward, foram indicativas, décadas atrás, da tomada de consciência por parte dos antropólogos norte-americanos da existência da nação. Nos anos 80, o que aconteceu, e não estou sendo evolucionista aqui, foi a tomada de consciência da existência de forças globais. E o seu livro Europe and the People Without History foi altamente influente nesse processo. Você começou sua carreira nos anos 50. Iniciando com Steward na década de 50 até os anos 90, como vê esses desenvolvimentos no tempo? Existem momentos, períodos? Foi apenas uma questão de construir categorias mais abrangentes ou de ter consciência de que os conceitos não eram mais capazes de explicar aquilo que se experimentava na pesquisa de campo?

\section{Wolf}

Houve uma grande mudança desde a época do difusionismo que contava traços e visava descobrir onde uma cultura terminava e a outra começava - e como os traços migravam de uma para outra. O que foi algo interessante. Tratase de uma dimensão de comunicação. 
M as chegou a extremos, tornou-se matematizado, formalizado. Então, vieram os estudos de aculturação que, qualquer que seja a forma que pensemos sobre eles hoje, foram a introdução de uma noção, de um campo de relações entre o povo " $A$ " e o povo " $B$ ", entre a cidade e o campo. Foi uma mudança importante. Levou a todo tipo de problemas, mas, em vez de apenas contar traços e reconstruir culturas tal como existiram no passado, havia a idéia de enfocar pessoas vivas interagindo, pessoas em diferentes tipos de cenários. Em certo sentido, então, o que o Steward faz é tomar esse campo de interações e representá-lo como um edifício, como uma arquitetura, onde existe um primeiro andar, as comunidades, depois um segundo andar, as regiões, e um terceiro, as nações. A gente nunca sabe muito bem como passar de um para o outro, mas...

\section{Lins Ribeiro}

E o nome dos andares pode variar.

\section{Wolf}

Pode variar. Era um esquema altamente imperfeito, mas agregou uma quarta dimensão à idéia de interações em um campo. O campo agora tem muitos planos, muitos níveis, são múltiplos campos. Acho que a mudança para a perspectiva global implica muito mais, não apenas explode tudo isso, mas qualquer que seja a arquitetura que permaneça é muito mais complicada.

\section{Lins Ribeiro}

Já se discutiu tanto sobre globalização que estamos chegando a um ponto de saturação. Mas a localização da pesquisa antropológica em cenários globais complica muito como fazer pesquisa e nós ainda ol hamos esse assunto de uma forma muito tradicional. Ainda se treina as pessoas em termos de "áreas do mundo". Talvez, e isto é uma provocação, se quisermos estudar tópicos e objetos globais possamos aprender mais sobre cultura afro-brasileira na cena global, focalizando escolas de samba em São Francisco (Califórnia), do que indo para o Rio ou para a Bahia. A cho que existe um reembaralhamento muito radical na forma como imaginamos dar conta de certas questões através da pesquisa.

\section{Wolf}

Existe, agora, uma multiplicidade de campos. Parece-me que também é necessário expandir essa visão para as pessoas, os indivíduos, o self. Há, no presente, tanta preocupação com a identidade, justo quando as identidades estão desaparecendo. Mas o self nunca foi uma coisa única. Freud falou em id, ego e superego, ao menos três níveis, há, provavelmente, muitos mais. Em um interessante artigo, Felix Keesing, pai de Roger Keesing, argumentava, muitos anos atrás, que na aculturação algumas coisas mudam mais facilmente que outras. Acho que os exemplos que ele deu eram errados, mas quando pensamos dessa forma, a noção de pessoa unitária aparece como falsa tanto quanto a de um grupo unitário. Processos incidem sobre eles, por exemplo, o ciberespaço repentinamente incide sobre todas as pessoas de um grupo, e vai diferenciar o grupo, o que causará efeitos distintos tanto sobre ele mesmo quanto sobre as pessoas. Assim, pessoas que tiverem aprendido a dançar samba podem se conectar com vários outros grupos de dança em diversos níveis, do popular a formas artísticas altamente elaboradas. Contudo, existem também obstáculos. Fui uma vez a um teatro ver o J osé Leguizamo, um comediante venezuelano, representando um personagem que era um hispânico, um imigran- 
te latino-americano que se fazia passar por japonês, ensinando hispânicos como vencer na vida seguindo modelos japoneses. O que acontece é que enquanto ele dava suas aulas, se alguém ligasse um aparelho e começasse a tocar cha-cha-cha suas pernas começavam automaticamente a mexer (risos) de acordo com o ritmo. Isto me chamou a atenção como um tipo peculiar de parábola, o tipo de fato que provavelmente acontece em vários níveis, naqueles diferentes níveis da pessoa diferenciadamente expostos a impulsos externos.

\section{Lins Ribeiro}

Vamos mudar um pouco. Ainda no âmbito do novo ambiente das ciências sociais e da antropologia. Talvez a coisa mais forte que aconteceu nos últimos dez anos foi o fim da União Soviética. Qual o impacto disto sobre a antropologia? Talvez em termos de economia, sociologia e ciência política esta seja uma questão mais evidente. Mas sempre existiu a relação entre o marxismo e o social ismo real. Uma vez que não existe mais o modelo real operando e aqui não importa tanto a nossa opinião sobre esse modelo, um espaço vazio se estabelece. Como você vê isto?

\section{Wolf}

Vamos falar primeiro sobre o marxismo. Acho que o que aconteceu com suas muitas variações foi que todas submergiram sob a ortodoxia stalinista. $\mathrm{Na}$ história das diferentes vertentes do marxismo há algumas mais culturológicas, outras menos, algumas mais social-democratas, outras utópicas etc. Eu sempre achei que essa riqueza de possibilidades deveria ter mais espaço. Agora se encontra muda, de certa forma. Quem é que vai ler todos esses caras? Marxismo positivista, materialismo dialético... Todas essas diferenças, creio, teriam feito o marxismo muito mais rico. Então, ficamos presos em um só modelo que não conseguia ser suficientemente flexível para acomodar a realidade. Existem outras razões. Uma delas é que o próprio sucesso do comunismo, no que se refere às relações étnicas na União Soviética, fornecendo a diversos povos identidades nacionais, permitindo o florescimento de culturas nacionais, de línguas, acabou tendo seus efeitos. Porque todas essas pessoas decidiram que, tendo sido educadas em academias marxista-leninistas, estavam prontas para assumir o poder. Bem, isto sobre o marxismo. Se ele sobreviver terá de ser de uma forma muito mais diversificada. Já a antropologia, pareceme, sempre teve problemas com o "poder" - o tipo de coisas de que falávamos antes -, nunca reconhece seus próprios aspectos políticos e o cenário político em que opera. Acho que ela perdeu o bonde durante a transição dos anos 80 . O Brian Ferguson organizou várias sessões na Academia de Ciências de Nova I orque e nos encontros da Associação Americana de Antropologia, nas quais os antropólogos falavam sobre lugares problemáticos no mundo, como eles entendiam a Bósnia, a Somália. Todas as apresentações foram extremamente interessantes, muito diferentes do que normalmente é descrito pela ciência política. Existe um antropólogo holandês chamado Mart Bax que escreveu um livro sobre um centro de peregrinação na Bósnia. Ele coloca os peregrinos, o Partido Comunista, os padres, o bispado, como atores em uma mesma situação, na qual todos estão interagindo para decidir sobre quem tem poder sobre quem. É uma visão antropológica, muito mais rica do que qualquer coisa que você possa obter nos meios de comunicação e que poderia contribuir para um seguimento e entendimento do conflito. 


\section{Lins Ribeiro}

Eric, você se definiria como um marxista na antropologia norte-americana?

\section{Wolf}

Sim, defino-me como um marxista simplesmente porque não quero dar a outros a satisfação de fazê-lo (risos). Existe algo forte no marxismo que é a procura de estruturas que governam relações concretas entre as pessoas. Não é o bastante, é um ponto para começar. M as se você não o tem, você se perde.

\section{Lins Ribeiro}

Então, como você acha que o marxismo continuará a se desenvolver, a mostrar sua face, na antropologia americana, com o fim do socialismo real? Existe algo já perceptível em muitos meios acadêmicos de diferentes países que é uma diminuição da presença do marxismo no discurso das pessoas...

\section{Wolf}

Eduardo Archetti me disse que percebeu que o marxismo estava em maus lençóis quando, na livraria da universidade, em Oslo, mudaram os livros sobre marxismo para os fundos da loja e colocaram, no lugar, livros de astrologia (risos). Eu nunca tive certeza sobre os prognósticos revolucionários do marxismo. A idéia do proletariado sempre me pareceu um primeiro passo interessante para perguntar quais eram as implicações do trabalho assalariado. $M$ as a idéia de um proletariado unificado que, então, atua em uníssono sob a liderança do Partido Comunista, sempre me pareceu uma quimera. Karl Wittfogel uma vez disse: Marx sim, marxismo não. A cho que o marxismo falhou intelectual e politicamente, mas deixa um importante legado a ser incrementado. Se vai sobreviver ou não, não tenho a menor idéia. Existe um certo nú- mero de pessoas como o William Roseberry, J oe Heyman, eu mesmo, que se autodenominam ecologistas políticos, que provavelmente continuarão um modo de análise que poderia ser chamado de marxista, ao menos em algumas das suas características. Mas somos uma espécie de marxistas marginais, em um certo sentido. Companheiros de viagem, mais do que crentes autênticos.

\section{Lins Ribeiro}

Um tópico associado é o do socialismo. Você ainda faz parte de um grupo de acadêmicos socialistas que se reúne periodicamente...

\section{Wolf}

Eles vão se encontrar de novo, proximamente, e estou considerando a idéia de ir a essa reunião. Ainda tenho minha assinatura da Monthly Review. Mas está se transformando em uma reunião de veteranos na qual você fala sobre as batalhas que uma vez lutou e espera algo melhor para o futuro. A não ser que tenha alguma coisa concreta que possa fazer com isso, se transforma em nostalgia.

\section{Lins Ribeiro}

Em uma época em que o capitalismo triunfante está por toda parte, o que devem fazer os socialistas?

\section{Wolf}

Alguém disse, acho que foi o Philippe Bourgois, "agora todos nós terminaremos sendo social-democratas" (risos)! $\mathrm{N}$ ão vejo nenhum programa geral. Mesmo nos lugares onde o socialismo realmente foi positivo, em Viena, por exemplo, a classe operária não acredita mais nele. Não tem apelo, todos querem fazer dinheiro. No final, teremos uma situação em que a metade do mundo en- 
riquece e a outra vive de rejeitos, homeless. A cho que é uma situação verdadeiramente horrível, humana, social e politicamente, em todos os sentidos. Mas não sei qual é a resposta.

\section{Lins Ribeiro}

Algumas pessoas, altamente respeitáveis, acham que a antropologia irá desaparecer. Você estudou em uma época em que a visão universal do antropólogo era muito forte. A fragmentação da especialização na antropologia é altíssima e pode ser vista nos encontros da Associação A mericana. Como poderá sobreviver essa visão universal dos antropólogos? Pode sobreviver? E isso tem a ver com uma de suas preocupações: uma perspectiva do tipo quatro campos boasianos (antropologia cultural, arqueologia, lingüística e antropologia física) sobreviverá em uma era de extrema fragmentação?

\section{Wolf}

Não tenho muita esperança de que sobreviverá. As instituições que costumavam ter uma perspectiva do tipo quatro campos estão rapidamente desmontando suas iniciativas, por várias razões. Mas acho, também, que existe um tipo de dialética entre a humanidade em geral e o enfoque de situações particulares. Quando investigamos situações específicas temos em mente uma comparação de todas essas situações. Tais perspectivas estão desaparecendo. As pessoas não querem mais fazer pesquisa de campo, ou a pesquisa de campo tem de ser a maior parte do tempo sobre a identidade do self, como eu me sinto quando falo com dois cheyennes. Antes nos detínhamos sobre eles, e não sobre nós. Essas coisas que estão desaparecendo, de certo modo definiam como a antropologia era, não sei o que será no futuro. Se não tivermos a noção geral do que faz a humanidade possível enquanto um projeto, e o que faz a humanidade existir de um certo modo em diferentes situações, se não tivermos essa combinação, então, quem precisará de antropologia? Essa é a sua marca de distinção. A observação naturalista também está sob ataque.

\section{Lins Ribeiro}

Mas isso também tem um lado positivo. A pretensão de "estar lá" e ser um observador neutro era algo em que muita gente acreditava. E agora não se pode mais montar a estória ingênua da neutralidade objetiva. Transformar tudo em um jogo de textos é o cerne da questão, pois pode-se chegar ao ponto em que as pessoas não querem mais fazer pesquisa de campo.

\section{Wolf}

Sem dúvida. Também tudo é implodido no plano do indivíduo, com questões como "quem sou eu em relação a essa outra pessoa". Assim, perde-se a capacidade de generalização que a antropologia teve no passado. Acho que há uma grande perda real de disciplinas baseadas na observação. A psicanálise, válida ou não, envolvia de fato a idéia de observar e ouvir alguém e, a partir de pequenas estórias e sinais, construir algum tipo de explicação. Isso praticamente desapareceu. Agora, enfiam uma pílula na pessoa e pronto. O mesmo com a antropologia. Os sociólogos são bem mais poderosos com as estatísticas, observações e entrevistas que desenvolvem, do que um cara sentado em "el barrio" tratando de entender o que está acontecendo. Assim, acho que o ângulo de observação natural do trabalho de campo irá desaparecer também. Isso é muito ruim, porque as alternativas para todos esses modelos serão os economistas do Banco Mundial. 


\begin{abstract}
Lins Ribeiro
Então, a particularidade da antropologia é ver o universal desde um ponto de vista particular que é densamente observado. Existe algo mais que gostaria de falar?
\end{abstract}

\title{
Wolf
}

Neste ponto da minha vida, o que realmente me fascina é que todas essas noções com as quais trabalhamos, de repente, só se mantêm juntas com clipe de papel. Não funcionam muito bem. Nesse projeto em que me encontro, o poder da imaginação humana de inventar idéias é realmente impressionante. Podem ser loucas ou não, têm conseqüências, matam pessoas. $M$ as existe realmente algo sobre elas que não capturamos muito bem. Pensemos sobre a história das Cruzadas; a idéia de converter o mundo inteiro ao islamismo, ou ao catolicismo; a idéia de que os judeus depois de 6 mil anos devem voltar à Palestina - e não importa quem viva lá, são recém-chegados que não pagaram aluguel por 2 mil anos. Essa capacidade dos humanos de criar projetos impressionantes é algo, para mim, bastante inexplicável. 